\title{
ESTEBAN TORRE: El ritmo del verso. Publicaciones de la Universidad de Murcia, Murcia, 1999 ( $1^{\mathrm{a}}$ reimpresión 2002$)$.
}

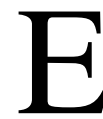

ntre las más recientes contribuciones a la ciencia de verso, hemos de destacar la publicación del libro El ritmo del verso (Estudios sobre el cómputo silábico y la distribución acentual, a la luz de la Métrica Comparada, en el verso español moderno) escrito por el profesor Esteban Torre, Catedrático de Teoría de la Literatura y Literatura Comparada en la Universidad de Sevilla. No es ésta, por supuesto, la primera incursión del profesor Torre en temas relacionados con la Métrica Comparada. Traductor y recreador de antiguos y modernos es también autor, entre otros estudios, de un importante tratado de Teoría de la traducción literaria (1994) y de un manual de Métrica española comparada (1999), modelo de claridad, sencillez y erudición. Estamos hablando pues de un verdadero especialista en la materia, que aúna en sus saberes la reflexión teórica y la praxis de la traducción poética sin olvidarnos, claro está, de su amable e inspirada relación con las musas, recogida en varios libros de poesía y de publicaciones periódicas.

Razones metodológicas llevan al profesor Torre a delimitar el corpus que sirve de base a su investigación: la comparación del verso español moderno y contemporáneo con el de otras lenguas principalmente el francés, el italiano, el portugués, el catalán, el inglés, el alemán y el ruso. A un lado quedan los problemas que se originan de la métrica medieval y de la métrica clásica, griega y latina, ya que, según nos dice, «se trata de modelos distintos de versos» (p.13). Así, a la luz del método comparativo sobre la teoría del ritmo, que tiene su base principal en la Teoría Métrica, de filiación estructuralista y generativista, y en la Fonética Acústica de carácter experimental, el profesor Torre analiza los debatidos y conflictivos conceptos sobre los que se fundamentan el cómputo silábico y la distribución de los acentos en el verso español. «Si me ocupo aquí, inicialmente, -dice-del número de 
sílabas y de la situación de los acentos, es porque considero que acento y sílaba constituyen el armazón básico e imprescindible del ritmo del verso» ${ }^{1}$ (p. 12). De ahí que este trabajo se nos presenta no solo como una acertada y sintética revisión de los principales tratadistas de métrica española y extranjera sino también como un esfuerzo serio y bien logrado de tratar de insertar los criterios métricos tradicionales en la teoría literaria moderna. Y aquí estriba precisamente su aporte fundamental.

Aunque El ritmo del verso no tiene un estricto carácter polémico, encierra sin embargo una toma de postura muy clara y convincente sobre la bibliografía al uso y los temas tratados. Sin afán de contradecir, menospreciar o anular, con un recto y honrado sentido crítico, el profesor Torre nos entrega sus propias opiniones en medio de otras de otros autores, diversas y contradictorias. Se trata nada menos, en algunos casos, de poner orden y concierto en el caos terminológico de la Teoría Métrica. En el capítulo segundo, "Regularidad métrica y versificación irregular”, donde además de hacer un repaso apoyado en fuentes bibliográficas especializadas sobre la coexistencia en la poesía española del verso regular y el verso libre y donde también considera inútil a la altura de nuestro tiempo oponer, como es usual en ciertos estudios recientes, los conceptos de metro y ritmo dice: "Prefiero, no obstante, utilizar ambos términos con el sentido más estricto que les confiere la teoría métrica: metro como "patrón abstracto” y ritmo como “patrón real” (p. 20).

De igual modo en el capítulo tercero, "Fundamentos fonéticos y fonológicos del ritmo”, insiste en la necesidad de precisar y aclarar el uso, desde la Fonética Acústica en relación con el cómputo silábico, de los conceptos de isocronía e isosilabia y su correspondiente y contradictoria clasificación de las lenguas naturales con tendencia unas a la isocronía acentual, o isocronía entre los pies acentuales, y otras con tendencia a la isosilabia, o isocronía silábica con anisocronía acentual. «Conviene -nos dice el catedrático andaluz- precisar el valor de estos términos, porque, en distintos contextos, y según los diversos autores, pueden aparecer investidos de muy dispares significados» (p. 27). Y más adelante puntualiza: «la clasificación de las lenguas en dos grandes grupos, con características métricas bien definidas, dista mucho de constituir un cuerpo de doctrina solidamente fundado. Y, desde luego, no puede basarse en esta división dicotómica de las lenguas

${ }^{1}$ El subrayado es nuestro. 
una separación tajante entre la métrica silábica y la métrica acentual» (p. 30). De ahí que considere insuficientes los meros criterios fonéticos y fonológicos como instrumentos de análisis que puedan ser aplicables sin más al estudio de la métrica. En cambio, el profesor Torre, encuentra en el principio de alternancia, desarrollado en el aspecto teórico desde la Fonología Métrica y en el práctico y experimental desde la Fonética Acústica, un patrón válido e incontrovertible para el estudio del ritmo y la escansión del verso. «El principio de alternancia -dijo- o lo que es lo mismo, de eufonía o euritmia, parte de la observación de que las lenguas evitan la sucesión de sílabas con el mismo grado de tensión, haciendo que alternen las sílabas fuertes con las sílabas débiles» (p. 30-31). Y es desde este punto de vista, con estimación de los mismos conceptos problemáticos de sílaba y acento como elementos básicos del metro, que términos como sinalefa y dialefa, diéresis y sinéresis, adquieren un nuevo sentido al no ser considerados de acuerdo con la preceptiva española tradicional, como simples"licencias poéticas" sino como hechos de habla que el poeta utiliza de manera intuitiva y espontánea. Conviene señalar que el profesor Torre, para confirmar su tesis de un modo objetivo y experimental, reproduce en su trabajo las gráficas de los fenómenos fonéticos implicados en la escansión del verso, intensidad y tono, especialmente este último, tomando como ejemplo la lectura de un poema de Federico García Lorca en el Laboratorio de Fonética de la Facultad de Filología de la Universidad de Sevilla. «El acento rítmico -dice- está en función, por lo tanto, no sólo de la intensidad acústica, sino también de la frecuencia fundamental o tono ${ }^{2}$ de cada una de las sílabas» (p. 45).

Este mismo espíritu crítico de revisión de conceptos, análisis de teorías y busca de claridad, que alienta la obra del profesor Torre, lo ejemplifica una vez más el capítulo cuarto, «El verso como unidad rítmica: el problema de los finales agudos, graves y esdrújulos”. Aquí el profesor Torre, como en otras ocasiones, se sitúa al lado de preceptistas tradicionales, como Juan Díaz de Rengifo o el mismo Ignacio de Luzán, y comparte con Domínguez Caparrós, principios y explicaciones de teoría métrica. Así, frente a las aseveraciones y elucubraciones sobre la teoría del verso como unidad rítmica de Canellada y Madsen, Quilis, Graña Etcheverry y el mismo Tomás Navarro Tomás, el profesor Torre sostiene que efectivamente el verso termina realmente en

${ }^{2}$ El subrayado es nuestro. 
la última sílaba acentuada y que la pausa es un factor demarcativo esencial, que distingue y separa los versos en la serie poemática: «si después de la última sílaba acentuada, -dijo- y precediendo a la pausa, aparecen una (en las palabras llanas) o dos (en las palabras esdrújulas) sílabas tónicas, es algo que carece de interés desde el punto de vista métrico» (p. 64). De ahí que podamos considerar el período de enlace como la sílaba o las sílabas postónicas finales, que median entre la última acentuada y la pausa. Conviene aclarar aquí que el profesor Torre no acepta la división de Navarro Tomás entre periodo rítmico interior y periodo rítmico de enlace porque, junto con Belic, ve en ella una concepción problemática y mecanicista con su sobrevaloración del concepto erróneo de anacrusis en total desacuerdo con la versología moderna que sostiene que en la poesía «la unidad rítmica fundamental es el verso, todo el verso» (p. 68). El profesor Torre cierra sus consideraciones con ejemplos tomados de la teoría métrica portuguesa, catalana, italiana y alemana.

El capítulo quinto, «La segmentación del verso: el alejandrino como paradigma» es, como lo indica el título, una aplicación de las teorías métricas y rítmicas aplicadas al estudio de las diversas clases de alejandrinos especialmente en lengua francesa y española. Del mismo modo que en los capítulos anteriores el profesor Torre discute, aclara y deduce términos y teorías, en éste se ocupa de la distinta, ambigua y compleja nomenclatura del verso alejandrino, inspirada fundamentalmente en la métrica francesa, para llegar a la conclusión de que «hemos finalmente de reconocer que tales peculiaridades en el verso alejandrino español no son más que variedades rítmicas de un mismo y único patrón métrico: el verso tetradecasilábico, compuesto por dos hemistiquios heptasílabos» (p. 96). Así pues las consideraciones de Henríquez Ureña sobre el alejandrino tripartito, de Andrés Bello sobre el alejandrino a la francesa, de Grammont sobre el alejandrino como verso simple, de Kibedi Varga sobre la dislocación o incluso destrucción del silabismo, y sobre todo del alejandrino, etc., quedan como bienintencionadas y eruditas referencias, que tal vez no haya que olvidar, pero que no resuelven los problemas que plantea la correcta distribución acentual y el cómputo silábico del verso alejandrino español y de otras lenguas y literaturas.

Termina El ritmo del verso del profesor Esteban Torre con “Algunas propuestas analíticas e interpretativas” que constituyen un verdadero prontuario teórico y metodológico, para el análisis e interpretación, desde la Métrica Comparada, de los elementos estructurales -cómputo silábico y distribución acentual- que están en la base del verso 
español moderno. Lo acompaña finalmente una bibliografía amplia, especializada, completa y puesta al día de la materia en cuestión.

En definitiva, El ritmo del verso es uno de esos libros, no tan frecuentes en nuestro medio, de lectura y consulta imprescindible para todos los estudiosos de la métrica y del ritmo del verso, especialmente profesores y alumnos de las facultades de filología, porque como bien se recuerda al comienzo del mismo, en palabras de Pietro Beltrami, «A chi non abbia interesse per la poesia la metrica non serve a niente».

Noel Rivas Bravo 